\title{
Activity of ethanolic extract of Clerodendrum violaceum leaves against Plasmodium berghei in mice
}

\author{
Balogun, E.A. ${ }^{1}$, Adebayo, J.O. ${ }^{1}$, Zailani, A.H. ${ }^{1}$, Kolawole, O.M. ${ }^{2 *}$, and Ademowo, O.G. ${ }^{3}$ \\ ${ }^{1}$ Department of Biochemistry, University of llorin, llorin, Kwara State, Nigeria. E-mail \\ addresses: topebayo2002@yahoo.com, Telephone: +234 7035487636 \\ ${ }^{2}$ Department of Microbiology, University of Ilorin, Ilorin, Kwara State, Nigeria. \\ ${ }^{3}$ Institute of Advanced Medical Research and Training, University College Hospital, Ibadan, \\ Oyo State, Nigeria. \\ *Corresponding author Email: tomak74@yahoo.com, Tel: +2348060088495 \\ ABSTRACT
}

\begin{abstract}
The antimalarial potential of the ethanolic extract of Clerodendrum violaceum leaves $(13 \mathrm{mg} / \mathrm{kg}$ body weight) was investigated in mice infected with Plasmodium berghei. Haematological indices including the red blood cell indices, the white blood cell indices and platelet count were also evaluated on days 3, 8 and 14 after infection. Phytochemical screening revealed a predominance of alkaloids (3.68 \%), and phenolics $(2.78 \%)$ in the extract. The extract suppressed parasitaemia following administration to infected mice by $92.3 \%$ on day 14 post-infection. The infected extracttreated animals had significantly higher $(P<0.05)$ red blood cell count $(R B C)$, packed cell volume (PCV), haemoglobin concentration ( $\mathrm{Hb})$, white blood cell count (WBC), and platelet count than the infected untreated animals. The results suggest that the extract possesses considerable antimalarial activity and may induce synthesis of red blood cells, white blood cells and platelets. These results support further studies on Clerodendrum violaceum leaf as a source of antimalarial remedy.
\end{abstract}

Keywords: Clerodendrum violaceum, ethanolic extract, phytochemicals, antimalarial activity.

\section{INTRODUCTION}

Malaria is an infectious disease that continues to be associated with considerable morbidity and mortality and significant social and economic impact in developing countries. More than 2 billion people are at risk of malaria (Snow et al., 2005) which is endemic in 91 countries, predominantly in Africa, Asia and Latin America. Traditional medicines have been used to treat malaria for many years and are the source of the two main groups of modern antimalarial drugs (artemisinin and quinine derivatives). These antimalarial drugs were derived from plants and are still effective in treating malaria (Bodeker and Willcox, 2000), although they are relatively expensive for the rural dwellers that are predominantly at risk of the disease. Thus, such people resort to cheaper available traditional medicines which are majorly herbs.

Although traditional medicine is widely used to treat malaria and is often more available and affordable than orthodox medicine, there are few clinical data on safety and efficacy. More so, there is no consensus, even among traditional healers, on which plants, preparations, and dosages are the most effective. On the whole, medicinal plants are just taken based on local reputation; one of such plants is Clerodendrum violaceum.

Clerodendrum violaceum Gürke (Verbenaceae) is commonly called Clerodendrum in English and Ewe isedun in Yoruba. It is a shrub with greenish flowers of up to one inch across. The genus Clerodendrum is widely distributed in the tropics and subtropics; with a few species extending into the temperate regions. It is found in countries like Ghana, Zimbabwe, Congo, Cameroon and Nigeria in Africa. In Nigeria, it is found in Lagos, Oyo and Kishi. The fresh leaves are used to resolve enlargement of lymphatic glands. A decoction of the leaves and root is taken for fever. Hot oil-coated leaves are used as dressing for fresh cuts and wounds. Boiled in oil, the roots are used as an embrocation in treating rheumatism. The decoction of the roots is used as antihelmintic (Bisht and Kundu, 1962). In Nigeria, a decoction of the leaves has been claimed to have antimalarial activity and is taken orally by the people in Kishi, Oyo town and environs.

Although this plant is used in the traditional treatment of malaria, there is no documented study of its antimalarial activity. This study was set out to scientifically validate this claim or prove otherwise. 


\section{MATERIALS AND METHODS}

Chemicals: Absolute ethanol (Riedel-de Haën) was obtained from Sigma-Aldrich Laborchemikalien $\mathrm{GmbH}$, Germany. Methanol was obtained from Eagle Scientific Limited, Nottingham. Giemsa stain was obtained from Anosantec Laboratories, UK. Immersion oil was obtained from Panzonar Laboratory Supplies, Button road, Canada. Chloroquine diphosphate salt was obtained from Sigma Chemical Company, St. Louis, Mo, USA. Other reagents used were of analytical grade and were prepared in all glass-distilled water.

Animals: Seventy five adult Swiss albino mice with an average weight of $20 \pm 2 \mathrm{~g}$ were obtained from the animal breeding unit of the Department of Biochemistry, University of Ibadan, Oyo state. The mice were housed in plastic cages and maintained under standard laboratory conditions with free access to rat pellets and tap water ad-libitum. The research adhered to the Principles of Laboratory Animal Care (NIH publication \#85-23, revised in 1985).

Parasites: A chloroquine-sensitive strain of Plasmodium berghei (NK-65) was obtained from the Institute for Advanced Medical Research and Training (IAMRAT), College of Medicine, University of Ibadan, Oyo state.

Plant materials: Fresh leaves of Clerodendrum violaceum were harvested in Oyo town of Oyo state in August 2006, and were authenticated at the Forestry Research Institute of Nigeria (FRIN), Ibadan, Oyo state.

Plant extract preparation and phytochemical screening: Fresh leaves of the plant were dried in the shade at room temperature and pulverized to powder using an electric blender. $200 \mathrm{~g}$ of the powder was percolated in $1600 \mathrm{ml}$ of absolute ethanol and kept in the shade for 48 hours after which it was filtered. The filtrate was collected in a beaker, exposed to air and allowed to evaporate at room temperature to yield the extract concentrate (Adebayo et al., 2003) giving a percentage yield of $8.3 \%$. Preliminary qualitative and quantitative phytochemical screening of the plant extract was carried out employing standard procedures (Harbone, 1983). The prepared extract was free of endotoxin.

Animal grouping and extract administration: The animals were randomly divided into 5 groups: A, B, $C, D$, and $E$ of fifteen mice each. Animals in groups $A$ and $B$ were not inoculated with parasite while those in groups $C, D$, and $E$ were inoculated from the same donor mouse. The percentage parasitaemia and the red blood cell count of the donor mouse was first determined using a haemocytometer and appropriate dilutions of the infected blood with isotonic saline was done. Each mouse in the infected groups was inoculated on day 0 , intraperitoneally with $0.2 \mathrm{ml}$ of infected blood containing about $1 \times 10^{7} \mathrm{P}$. berghei parasitized red blood cells. Treatment was withheld for 72 hours to allow for establishment of infection and was commenced when parasitaemia was established by screening for malaria parasites in tail blood of infected animals after fixing in methanol and staining with Giemsa stain (Ryley and Peters, 1970).

Aqueous preparations of the extract corresponding to $13 \mathrm{mg} / \mathrm{kg}$ body weight, an optimum dose arrived at from preliminary studies (Zailani, Unpublished data) and chloroquine (corresponding to $4 \mathrm{mg} / \mathrm{kg}$ body weight) was made before administering orally to the mice. The administration of the extract and chloroquine which lasted for 5 days (days $3-7$ postinfection) is as follows:

Group A (uninfected mice): received an appropriate volume of sterile distilled water.

Group B (uninfected mice): received the aqueous preparation of the extract $(13 \mathrm{mg} / \mathrm{kg}$ body weight daily).

Group C (infected mice): received an appropriate volume of sterile distilled water.

Group D (infected mice): received the aqueous preparation of the extract $(13 \mathrm{mg} / \mathrm{kg}$ body weight daily).

Group E (infected mice): received the aqueous solution of chloroquine (4 mg/kg body weight daily).

Sample collection and analyses: Daily blood films were made from tail blood of all the infected animals (Groups C, D, and E) and the percentage parasitemia obtained through microscopic determination. Also, the percentage chemosuppression was calculated by subtracting the average percentage parasitemia in the treated group from the average percentage parasitemia in the control group and the value obtained was expressed as a percentage of the average percentage parasitemia in control group.

Four animals were sacrificed from each of the five groups on days 3,7 and 14 post-infection for collection of blood sample used for haematological evaluation. The animals were sacrificed by slight ether anesthesia and blood was collected by cardiac puncture into bottles containing EDTA as anticoagulant to prevent it from clotting; the samples were then used for haematological evaluations. Haematological evaluation was done using the automated haematological analyzer SYSMEX KX21 
(SYSMEX Corporation, Japan) (Malomo et al., 2002). Thus, red blood cell count (RBC), packed cell volume (PCV), haemoglobin concentration $(\mathrm{Hb})$, mean corpuscular haemoglobin $(\mathrm{MCH})$, mean corpuscular haemoglobin concentration (MCHC), mean corpuscular volume (MCV), white blood cell count (WBC), percentage neutrophils, percentage lymphocytes and platelet count were determined. The remaining animals were left for further two weeks post-infection.

Statistical analysis: Values are expressed as mean \pm SEM. The data were statistically analyzed using one-way analysis of variance (ANOVA) and Duncan Multiple Range Test (Mahajan, 1997). Data from the test groups were compared with their respective controls and differences at $\mathrm{P}<0.05$ were considered significant.

\section{RESULTS}

Some of the phytochemicals present in the ethanolic extract of Clerodendrum violaceum leaves are shown in Table 1. The extract possessed high concentrations of alkaloids and phenolics.

Table 1: Phytochemicals of the ethanolic extract of Clerodendrum violaceum leaves

\begin{tabular}{|lc|}
\hline Phytochemicals & Concentration (\%) \\
\hline Alkaloids & $3.71 \pm 0.03$ \\
Tannins & $1.02 \pm 0.05$ \\
Phenolics & $2.77 \pm 0.02$ \\
Glycosides & $0.07 \pm 0.00$ \\
Saponins & $0.10 \pm 0.01$ \\
Flavonoids & $0.36 \pm 0.02$ \\
Steroids & $0.30 \pm 0.02$ \\
Triterpenes & $0.10 \pm 0.02$ \\
Anthraquinones & $0.59 \pm 0.03$ \\
\hline
\end{tabular}

Values are means of 3 determinations \pm Standard deviation

Parasitaemia levels in infected untreated mice, infected mice orally treated with $13 \mathrm{mg} / \mathrm{kg}$ body weight of ethanolic extract of Clerodendrum violaceum leaves and infected mice treated with $4 \mathrm{mg} / \mathrm{kg}$ body weight of chloroquine from the fourth to the twentyeighth day of infection are shown in Figure 1. The extract treated group did not show significant reduction in parasitaemia initially until day 7 and thereafter continued to decline steadily; the chloroquine treated group on the other hand showed a steady decline from the first day of treatment. By day 28 , the parasitaemia had gone below detectable levels in both treated groups. The same trend was observed from the numerical values of percentage chemosuppression caused by treatment with the extract and chloroquine (Table 2).

Hematological indices in all study groups on days 3 , 8 , and 14 after infection are shown in Tables 4. Apart from the significant increase $(P<0.05)$ in WBC of the infected animals, there was no significant difference $(P>0.05)$ in all the other haematological parameters studied on day 3 when compared with controls. Administration of the plant extract $(13 \mathrm{mg} / \mathrm{kg}$ body weight) to uninfected mice produced significant increase $(P<0.05)$ in $\mathrm{RBC}, \mathrm{PCV}, \mathrm{Hb}, \mathrm{WBC}$, and platelet count compared to animals in other experimental groups on day 8. Although there was a significant decrease $(\mathrm{P}<0.05)$ in these parameters in the infected extract-treated group and the infected chloroquine-treated group when compared with the uninfected groups, however these two groups (infected treated) had significantly higher $(P<0.05)$ values for these parameters compared to the infected untreated group except the platelet count.

Moreover, the RBC, PCV, and $\mathrm{Hb}$ of the infected chloroquine-treated group were significantly higher $(P<0.05)$ than those of the infected extract-treated group. The observation made on day 8 , to a large extent, was similar to that of day 14 . However, the WBC and platelet count of the infected chloroquinetreated group were significantly higher $(P<0.05)$ than those of the infected extract-treated group while there was no significant difference $(P>0.05)$ between the haematological parameters of both uninfected groups.

\section{DISCUSSION}

The phytochemical screening of the ethanolic extract of Clerodendrum violaceum leaves revealed the presence of alkaloids and phenolics, having the highest percentage values (Table 1). The observed antimalarial activity (Fig. 1) may be attributed to its high alkaloid and phenolic contents. These compounds have been previously shown to be responsible for the antimalarial activities of many plants (Milliken, 1997; Abo et al., 1999; Okokon et al., 2005). The antimalarial activity observed in this study could be attributed to single or combined effect of these compounds although no active principle has been identified. The antimalarial activity of alkaloids of cinchona has been reported (Baranger, 1943). Phenolics are well known for their diverse physiological properties, including among others, anti-carcinogenic, anti-inflammatory and anti-parasitic properties (Hilou et al., 2006). 


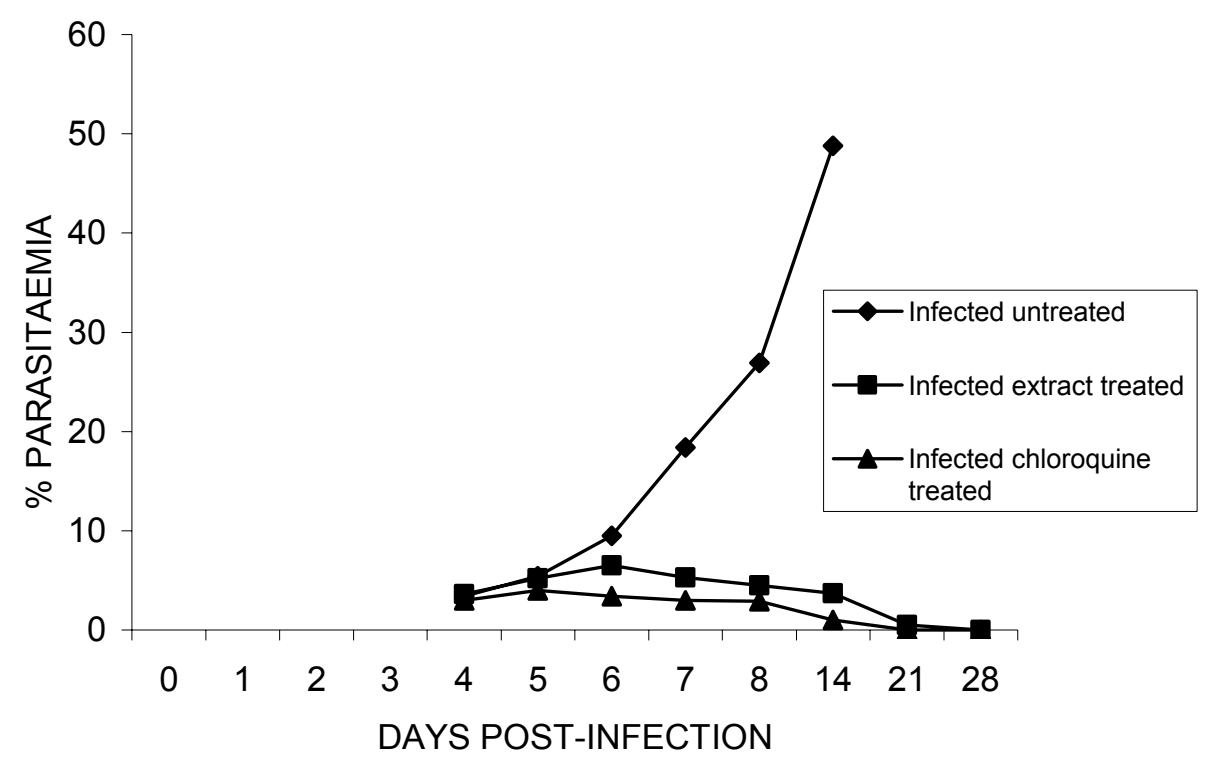

Fig 1: Percentage parasitaemia of mice placed on different treatments. Each point is an average count from five infected mice.

The initial low percentage chemosuppression observed in the extract-treated group compared to the chloroquine-treated group (Table 2) may be due to the fact that the extract at the dose administered had not accumulated sufficiently to bring about considerable chemosuppression (Adebayo et al., 2003) or it has a lower speed of action compared to chloroquine. However, the prolonged administration of the extract led to the total clearance of the parasites. This results from accumulation of enough active compounds to effect total clearance of the parasites. From day 7, the percentage chemosuppression of the extract was favourably comparable to that of chloroquine.

Haematological indices were considered in this study because the most pronounced changes related to malaria involve the blood and the blood-forming system. Anaemia is a fairly common problem encountered in malaria. This is evidenced by the decrease in $\mathrm{RBC}, \mathrm{PCV}$ and $\mathrm{Hb}$ in all the infected animal groups. This was obvious from day 8 postinfection in the infected groups and it persisted more significantly in the infected untreated animals till day 14 (Table 3). The observed decreases may be due to multiple causes, of which repeated haemolysis of infected red cells is the most important. The haemolysis may be due to non-immune destruction of parasitized red cells in case of high parasitemia or immune mediated destruction of parasitized as well as non-parasitized red cells because the changes in the red cell antigen structure brought about by the parasitic invasion stimulate the production of antibodies against the red cell. This triggers immunemediated red cell lysis. In addition, the growing parasite consumes and degrades the intracellular proteins which are mainly hemoglobin (Gavigan et al., 2001). This may account further for the decrease in $\mathrm{Hb}$. These decreases however were considerably reversed in the infected extract-treated and infected chloroquine-treated groups on day 14 post-infection. This suggests that the extract may have some stimulatory effect on the production of red blood cells (erythropoiesis). This might have contributed to the increase in PCV, $\mathrm{RBC}$ and $\mathrm{Hb}$ observed in the infected extract-treated group on day 14 postinfection (Table 3).

The observed increase in WBC in the infected animal groups on day 3 post-infection may result from stimulation of the immune system of the animals to fight the malaria parasites (Table 4). White blood cells function mainly to fight infection, defend the body by phagocytosis against invasion by foreign organisms, and to produce, transport and distribute antibodies in the immune response. On day 8 postinfection, there was a decrease in WBC in all the infected groups. This may imply a reduction in the ability of the mice to resist the infection (Yakubu et al., 2007). However, WBC in the infected extracttreated and infected chloroquine-treated groups was higher than in the infected untreated animals. This 
suggests a boost in the immune system by the extract and reference drug. On day 14 post-infection, there was a continued decrease in WBC in the infected untreated group which correlates with a high parasitaemia and other derangements as a result of the infection. The significant increase in WBC displayed by infected-extract treated and infectedchloroquine treated groups indicates an improved ability of the mice to combat the infection as a result of treatment. The boost in the level of WBC in the uninfected extract-treated group (day 8 postinfection) showed a significant decline a week after treatment was withdrawn (day 14 post-infection). This implies that the increase was induced by extract and the effect is reversible (Table 4).

On day 8 post-infection, there was a decrease in the level of platelets in the infected groups (Table 4). Like red blood cells, platelets are anuclear and discoid; they measure 1.5-3.0 $\mu \mathrm{m}$ in diameter. The body has a very limited reserve of platelets, so they can be rapidly depleted (Wagner and Burger, 2003). Decreased platelet count is also fairly common in malaria and may result from sequestration of platelets in the spleen (Horstmann et al., 1981). The uninfected extract-treated group showed an increase in platelet count. The increase in platelets in the latter group suggests the extract's stimulatory effect on platelet production, possibly by enhancing thrombopoietin's secretion (Malomo et al., 2002). By day 14 post-infection, there was a continuous drop in the level of platelets in the infected untreated group as a result of continued infection. The infected extract-treated and infected chloroquine-treated groups showed a significant increase in platelet count compared to the infected untreated group, still suggesting a stimulatory effect of the extract on platelet production. The initially observed increase in platelet count in the uninfected extract-treated group was reversed with a value comparing favourably with that of uninfected untreated group on day 14 due to withdrawal of the extract (Table 4).

Table 2: Percentage chemosuppression by the ethanolic extract of Clerodendrum violaceum leaves

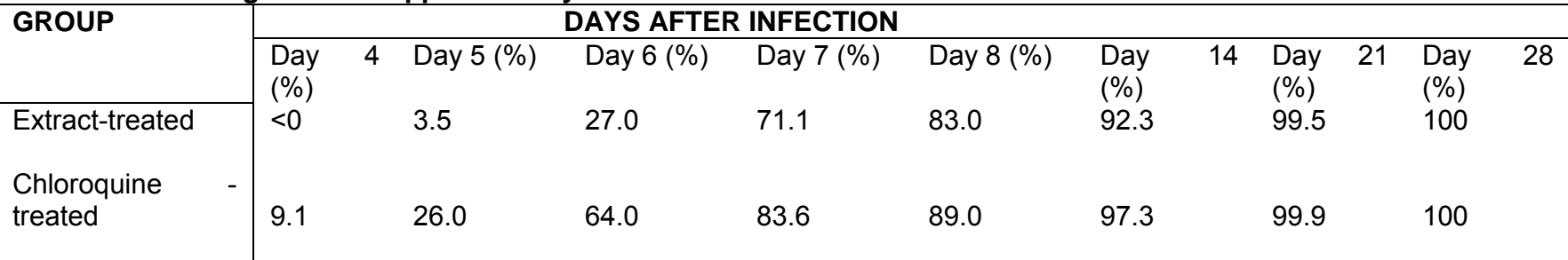

Table 3: Red blood cell indices of experimental animals

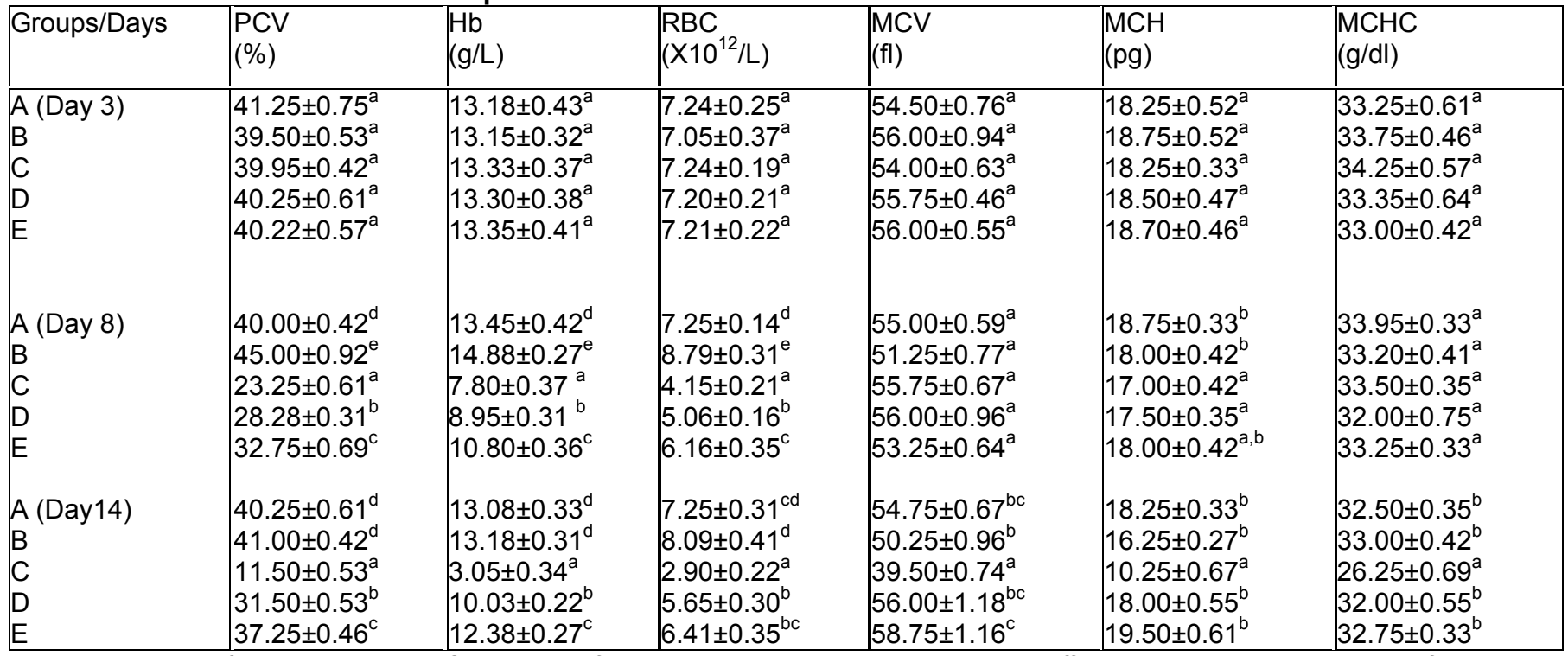

Values are means of 4 determinations \pm SEM. Values for each day along the same column with different superscript letters are significantly different $(P<0.05)$. 
Table 4: White blood cell indices and platelet counts of experimental animals

\begin{tabular}{|l|l|l|l|l|}
\hline Groups/days & $\begin{array}{c}\text { WBC } \\
\left(X^{9} / \mathrm{L}\right)\end{array}$ & $\begin{array}{l}\text { Platelets } \\
(\text { X10 } / \mathrm{L})\end{array}$ & Neutrophils (\%) & Lymphocytes (\%) \\
\hline A (Day 3) & $7.53 \pm 0.27^{\mathrm{a}}$ & $679.00 \pm 1.64^{\mathrm{a}}$ & $62.25 \pm 0.93^{\mathrm{a}}$ & $37.75 \pm 0.93^{\mathrm{a}}$ \\
B & $7.40 \pm 0.24^{\mathrm{a}}$ & $675.00 \pm 1.85^{\mathrm{a}}$ & $63.00 \pm 0.63^{\mathrm{a}}$ & $38.00 \pm 0.63^{\mathrm{a}}$ \\
C & $9.08 \pm 0.30^{\mathrm{b}}$ & $678.25 \pm 1.46^{\mathrm{a}}$ & $60.25 \pm 0.93^{\mathrm{a}}$ & $39.75 \pm 0.93^{\mathrm{a}}$ \\
D & $9.28 \pm 0.45^{\mathrm{b}}$ & $674.25 \pm 1.58^{\mathrm{a}}$ & $61.25 \pm 1.10^{\mathrm{a}}$ & $38.75 \pm 1.06^{\mathrm{a}}$ \\
E & $9.10 \pm 0.48^{\mathrm{b}}$ & $676.00 \pm 1.95^{\mathrm{a}}$ & $59.75 \pm 1.03^{\mathrm{a}}$ & $40.25 \pm 1.03^{\mathrm{a}}$ \\
\hline A (Day 8) & $7.65 \pm 0.34^{\mathrm{c}}$ & $679.75 \pm 2.34^{\mathrm{b}}$ & $62.0 \pm 1.07^{\mathrm{b}}$ & $38.00 \pm 1.07^{\mathrm{a}}$ \\
B & $9.13 \pm 0.19^{\mathrm{d}}$ & $697.15 \pm 2.50^{\mathrm{c}}$ & $44.25 \pm 0.90^{\mathrm{a}}$ & $55.75 \pm 0.90^{\mathrm{b}}$ \\
C & $3.78 \pm 0.30^{\mathrm{a}}$ & $524.25 \pm 4.28^{\mathrm{a}}$ & $39.25 \pm 1.15^{\mathrm{a}}$ & $60.75 \pm 1.15^{\mathrm{b}}$ \\
D & $4.83 \pm 0.34^{\mathrm{b}}$ & $557.50 \pm 2.69^{\mathrm{a}}$ & $43.00 \pm 1.26^{\mathrm{a}}$ & $57.00 \pm 1.26^{\mathrm{b}}$ \\
E & $5.38 \pm 0.41^{\mathrm{b}}$ & $563.25 \pm 2.80^{\mathrm{a}}$ & $56.50 \pm 0.76^{\mathrm{b}}$ & $43.50 \pm 0.76^{\mathrm{a}}$ \\
\hline A (Day 14) & $7.78 \pm 0.19^{\mathrm{d}}$ & $677.85 \pm 1.42^{\mathrm{cd}}$ & $60.25 \pm 0.79^{\mathrm{b}}$ & $39.75 \pm 0.79^{\mathrm{a}}$ \\
B & $7.65 \pm 0.13^{\mathrm{d}}$ & $686.75 \pm 1.00^{\mathrm{d}}$ & $60.65 \pm 0.75^{\mathrm{b}}$ & $39.35 \pm 0.75^{\mathrm{a}}$ \\
C & $2.80 \pm 0.23^{\mathrm{a}}$ & $235.25 \pm 2.13^{\mathrm{a}}$ & $34.00 \pm 0.94^{\mathrm{a}}$ & $66.00 \pm 0.94^{\mathrm{b}}$ \\
D & $4.95 \pm 0.31^{\mathrm{b}}$ & $568.45 \pm 2.00^{\mathrm{b}}$ & $58.25 \pm 0.85^{\mathrm{b}}$ & $41.75 \pm 0.85^{\mathrm{a}}$ \\
E & $5.70 \pm 0.36^{\mathrm{c}}$ & $641.75 \pm 2.97^{\mathrm{c}}$ & $59.50 \pm 0.92^{\mathrm{b}}$ & $40.25 \pm 0.96^{\mathrm{a}}$
\end{tabular}

Results are means of 4 determinations \pm SEM. Values for each day along the same column with different superscript letters are significantly different $(P<0.05)$.

\section{CONCLUSION}

It may be concluded that the administration of the ethanolic extract of Clerodendrum violaceum leaves in an animal model of malaria was able to suppress established malarial infection and cause a boost in the production of red blood cells and some of its related indices as well as white blood cells and platelets. Further studies on Clerodendrum violaceum as a source of antimalarial remedy are indicated on the basis of these results.

\section{ACKNOWLEDGEMENTS}

We thanked the Institute for Advanced Medical Research and Training (IAMRAT), College of Medicine, University of Ibadan, Oyo state for the provision of the Plasmodium berghei strain.

\section{REFERENCES}

Abo K.A, Ogunleye V.O, Ashidi J.S. (1999) Antimicrobial potential of Spondias mombin, Croton zambesicus, and Zygotritonia crocea. Phytother Res 13: 494 -497

Adebayo J.O, Yakubu M.T, Egwim E.C, Owoyele B.V, Enaibe B.U. (2003) Effect of ethanolic extract of Khaya senegalensis stem bark on some biochemical parameters on rat Kidney. J Ethnopharmacol 88:69-72.

Baranger $\mathrm{P}(1943)$ The Action on Avian Malaria of the Alkaloids of Cinchonas from the Cameroons and the Belgian Congo. Parasitol 37: 342-344.

Bisht B.S, Kundu B.C. (1962) Pharmacognostic study of root and leaf of Clerodendrum serratum (L.) Moon. J Sci Ind Res. 21C, 3, 79-83.

Bodeker G, Willcox M.L. (2000) Conference report: the first international meeting of the Research Initiative on Traditional Antimalarial Methods (RITAM). J Alt Compl Med 6:195-207

Gavigan C.S, Dalton J.P, Bell A. (2001) The role of aminopeptidases in haemoglobin degradation in Plasmodium falciparum-infected erythrocytes. Mol Biochem Parasitol 117(1): 37-48.
Harbone J.B. (1983) Phytochemical Methods. A guide to Modern Techniques of Plant Analysis.: Chapman and Hall, New York.

Hilou A, Nacoulmaa O.G (2006) Guiguemde T.R. In vivo antimalarial activities of extracts from Amaranthus spinosus L. and Boerhaavia erecta L. in mice. J Ethnopharmacol 103: 236-240.

Horstmann R.D, Dietrich M, Bienzle U, Rasche H. (1981) Malaria-induced thrombocytopenia. Ann Haematol 42(3): $157-164$.

Mahajan B.K. (1997) Significance of difference in mean. In: Methods in Biostatistics for medical and research workers. 6th edition. JAYPEE Brothers Medical Publishers, New Delhi, pp. 130-155.

Malomo S.O, Adebayo J.O, Olorunniji F.J. (2002) Modulatory effect of vitamin $E$ on some haematological parameters in dihydroartemisinin - treated rats. The Tropical Journal of Health Sciences 9: 15-20.

Milliken W. (1997) Malaria and Antimalarial Plants in Roraima, Brazil. Trop Doct 27: 20-24.

$\mathrm{NIH}$. (1985). Guide for the care and use of laboratory animals. NIH publication No. 85-23, Revised

Okokon J.E, Ofodum K.C, Ajibesin K.K, Danladi B, Gamaniel K.S. (2005) Pharmacological screening and evaluation of antiplasmodial activity of Croton zambesicus against Plasmodium berghei berghei infection in mice. Ind $\mathrm{J}$ Pharmacol 37: 243-246.

Ryley J.F, Peters W. (1970) The antimalarial activity of some quinolone esters. Am J Trop Med Parasitol 84: 209-222.

Snow R.W, Guerra C.A, Noor A.M, Myint H.Y, Hay SI. (2005) The global distribution of clinical episodes of Plasmodium falciparum malaria. Nature. 434: 214-217.

Wagner D.D, Burger P.C. (2003) Platelets in inflammation and thrombosis. Arterioscler Thromb Vasc Biol 23: 21312137.

Yakubu M.T, Akanji M.A, Oladiji A.T. (2007) Hematological evaluation in male albino rats following chronic administration of aqueous extract of Fadogia agrestis stem. Phcog Mag 3(9): 34-38.

Zailani A.H. Unpublished data. 